\title{
Musculoskeletal symptoms and workers' perception about job factors in a pulp and paper industry
}

\author{
Marina Zambon Orpinelli Coluci ${ }^{\mathrm{a},{ }^{*}}$ Neusa Maria Costa Alexandre ${ }^{\mathrm{a}}$ and Thais de Freitas Pedrini ${ }^{\mathrm{a}}$ \\ ${ }^{a}$ Department of Nursing, Faculty of Medical Sciences, PO Box 6111, University of Campinas - UNICAMP, Zip \\ Code 13083-970, Campinas, SP, Brazil
}

\begin{abstract}
The study aimed to conduct a literature review as a step of the development of a new questionnaire about the nursing workers' perception of job factors that may lead to musculoskeletal symptoms. An information synthesis was achieved by collecting data from studies that fitted the search criteria. The results showed that despite the existence of several job factors related to musculoskeletal symptoms, no specific questionnaire that evaluates this relationship was found. Therefore, this literature review presents important topics for developing the first questionnaire to analyze work activities that may contribute to pain and discomfort among nursing personnel.
\end{abstract}

Keywords: Work-related musculoskeletal disorders, job factors, nursing

\section{Introduction}

Musculoskeletal disorders are considered the major cause of morbidity and disability in adults (Smedley et al., 2003; Weiner and Nordin, 2010). Due to its high occurrence, musculoskeletal disorders generate greater costs of health care (Baldwin, 2004; Marras et al., 2009) and represent a major cause of occupational and disability problems among industrially developed and developing countries.

The aim of this study was to evaluate the musculoskeletal symptoms and the perception about jobfactors that may contribute to them, and also to identify the relationship between the intensity of pain and disability in workers from a pulp and paper industry.

\section{Methods}

The study was carried out at the "finish area" of a paper and pulp industry located in São Paulo State, Brazil. This area is responsible for cutting and packing all produced paper.
The study included workers with different functions and with time admission over three months and who were discharged by the supervisors during data collection. Service providers and those on sick leave were excluded.

Data collection was performed through individual interviews in a private place in the industry, using the instruments "Identification Questionnaire", "Brazilian version of the Nordic Questionnaire", and "Brazilian version of the Job Factors Questionnaire". For workers with musculoskeletal symptoms, the "Brazilian version of the Pain Disability Questionnaire (PDQ)" and the "Numeric Pain Scale" were also applied.

Descriptive analysis described the sample according to sociodemographic variables, musculoskeletal symptoms, job factors, disability caused by pain, and pain intensity. The Cronbach's alpha was used to assess internal consistency of the PDQ. The MannWhitney test was used to compare the perception of job factors among individuals with and without symptoms, and the Spearman correlation coefficient

\footnotetext{
*Corresponding author. E-mail: marinazo@fcm.unicamp.br.
} 
to verify the correlation between disability and pain intensity among symptomatic workers.

\section{Results}

The results showed that most workers $(63.4 \%)$ presented musculoskeletal symptoms, especially in the spine and shoulders (Figure 1).

Figure 1

Data obtained with the Nordic Questionnaire among workers from a pulp and paper industry $(\mathrm{N}=112)$.

\begin{tabular}{|c|c|c|c|c|}
\hline Body part & $\begin{array}{l}\text { Problems during } \\
\text { the last } 3 \text { months } \\
\text { in }(\%):\end{array}$ & $\begin{array}{l}\text { Problems during } \\
\text { the last } 7 \text { days in } \\
(\%):\end{array}$ & $\begin{array}{c}\text { Normal activities } \\
\text { prevented from } \\
\text { your problem in } \\
(\%):\end{array}$ & $\begin{array}{l}\text { Health care } \\
\text { utilization in the } \\
\text { last } 3 \text { months } \\
\text { because of your } \\
\text { problem in (\%): }\end{array}$ \\
\hline Neck & 15,5 & 1,8 & 1,8 & 6,4 \\
\hline$\rightarrow$ Shoulder & 28,2 & 5,5 & 6,4 & 11,8 \\
\hline Upper back & 23,6 & 2,7 & 2,7 & 5,5 \\
\hline Elbows & 7,3 & 2,7 & 3,6 & 5,5 \\
\hline Nrists/hanc & 15,5 & 0,9 & 0,0 & 3,6 \\
\hline Low back & 29,1 & 4,5 & 6,4 & 10,9 \\
\hline Hips/thighs & 9,1 & 3,6 & 2,7 & 2,7 \\
\hline Knees & 14,5 & 2,7 & 1,8 & 8,2 \\
\hline & 17,3 & 0,9 & 0,9 & 6,4 \\
\hline
\end{tabular}

The normal activities prevented by pain and health care utilization showed the interference of these symptoms in workers' lives.
Perceived most problematic job factors were those involving repetitive work, weight lifting, static work, and awkward postures (Figure 2).

Figure 2

Representation of the mean score of the Job Factors Questionnaire among the workers from a pulp and paper industry $(\mathrm{N}=112)$.

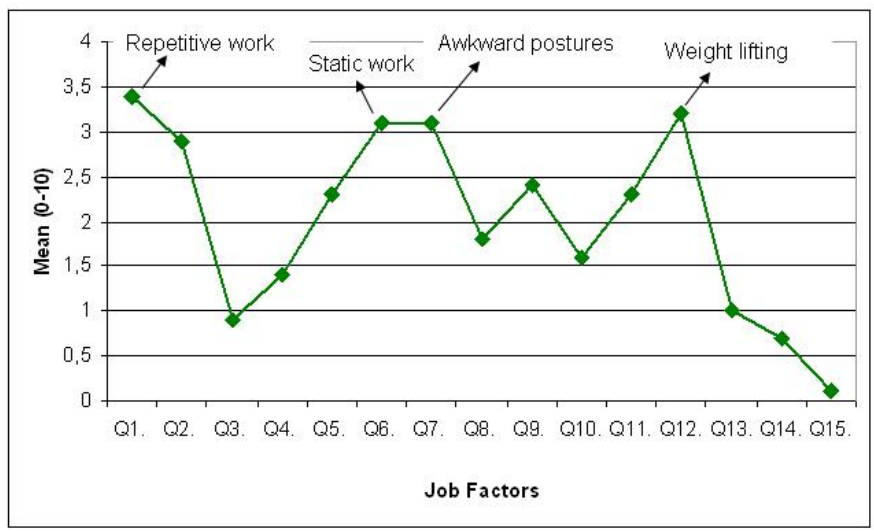


The comparison between symptomatic and asymptomatic subjects showed significant difference $(p<0.05)$ in their perception of nine job-factors.

An average pain intensity of 3.4 was found and the scores of the PDQ pointed to moderate disability in symptomatic workers.
The PDQ showed good internal consistency with Cronbach's alpha of 0.86 for the Functional Condition, of 0.74 for the Psychosocial Component, and of 0.90 for the total PDQ.

There was a significant correlation of moderate magnitude $(\mathrm{r}=0.40)$ between pain intensity and disability (Table 1).

Table 1

Spearman correlation coefficient between the Numeric Pain Scale and the Pain Disability Questionnaire (PDQ) among symptomatic workers $(\mathrm{N}=71)$.

\begin{tabular}{ccc}
\hline & r* & p-value \\
\hline Functional Condition & 0,4036 & 0,0005 \\
Psychosocial Component & 0,4270 & 0,0002 \\
Total & 0,4074 & 0,0004 \\
\hline
\end{tabular}

\section{Discussion and Conclusions}

The high prevalence of musculoskeletal symptoms, of being unable to perform normal activities, and of health care utilization is warning for installation of work disability. This study also identified same occupational factors that the literature has associated with the development of musculoskeletal disorders. These findings may provide support for implementing ergonomic changes and prevention programs in the "finish area" of the pulp and paper industry studied.

\section{References}

[1] J. Smedley, F. Trevelyan, H. Inskip, P. Buckle, C. Cooper, D. Coggon, Impact of ergonomic intervention on back pain among nurses. Scand. J. Work Environ. Health 29(2003):11723.

[2] S.S. Weiner, M. Nordin, Prevention and management of chronic back pains. Best. Pract. Res. Clin. Rheumatol 24(2010):267-79.

[3] M.L. Baldwin, Reducing the costs of work-related musculoskeletal disorders: targeting strategies to chronic disability cases. J. Electromyogr. Kinesiol 14(2004):33-41.

[4] W.S. Marras, R.G. Cutlip, S.E. Burt, T.R. Waters, National occupational research agenda (NORA) future directions in occupational musculoskeletal disorder health research. Appl. Ergon. 40(2009):15-22. 